\title{
Pelatihan dan Pendampingan Usaha Kecil Mikro Bengkel Mobil di Kabupaten Purworejo untuk Meningkatkan Daya Saing dan Pelayanan
}

\author{
Arif Susanto* \\ Pendidikan Teknik Otomotif Universitas Muhammadiyah Purworejo \\ Jalan K.H.A Dahlan No. 3 Purworejo, 54111, Jawa Tengah, Indonesia \\ *Email korespondensi: arif susanto360@yahoo.com
}

\begin{abstract}
Abstrak - Bisnis usaha bengkel mobil tidak hanya bertumpu pada kegiatan pelayanan perawatan mobil, tetapi didukung fasilitas yang nyaman dan pelayanan prima. Bengkel mobil"Karunia"merupakan usaha kecil mikro dengan sejumlah keterbatasan, diantaranya adalah keterbatasan jenis jasa layanan servis, sarana prasarana, sumber dana, dan kemampuan mengelola bengkel. Tujuan dari pelatihan ini meliputi service mobil berteknologi injeksi, penerapan sistem administrasi bengkel, penyusunan laporan keuangan, manajemen pemasaran, dan manajemen Lingkungan Keselamatan dan Kesehatan Kerja (LK3). Subyek sasarannya kegiatan adalah pengelola bengkel dan tenaga mekanik. Evaluasi kepuasan peserta pelatihan yang dilakukan melalui instrumen pengukuran kepuasan pelanggan. Hasil dari kegiatan pengabdian pelatihan dan pendampingan usaha kecil mikro bengkel mobil di kabupaten purworejo untuk meningkatkan daya saing pelayanan ini adalah; 1) kegiatan pengabdian yang dilaksanakan pada Bengkel Mobil "Karunia", mendapatkan respon yang cukup baik. Indikatornya adalah baik pengelola maupun tenaga mekanik bengkel mobil mitra mengikuti kegiatan dari awal hingga akhir; 2) kegiatan pelatihan dan pendampingan kepada pengelola dan tenaga mekanik bengkel mobil, telah meningkatkan pengetahuan tentang teknologi injeksi dan servis terhadap mobil berteknologi injeksi, kewirausahaan dan manajemen pemasaran, sistem administrasi bengkel, pencatatan laporan keuangan, dan manajemen lingkungan, keselamatan dan kesehatan kerja (LK3); dan 3) kgiatan pelatihan dan pendampingan telah memberikan bekal bagi pengelola dan tenaga mekanik bengkel mobil untuk lebih siap dalam memberikan jasa layanan servis mobil injeksi.
\end{abstract}

Kata Kunci : bengkel mobil, pendampingan, pelayanan, daya saing

\section{Training and Assistance for Small and Micro Car Repair Businesses in Purworejo Regency to Improve Competitiveness and Services}

\begin{abstract}
The car repair business business does not only rely on car maintenance services, but is supported by comfortable facilities and excellent service. The "Karunia" car repair shop is a small and micro business with a number of limitations, including limitations on the types of service services, infrastructure, sources of funds, and the ability to manage the workshop. The objectives of this training include injection technology car service, implementation of a workshop administration system, preparation of financial reports, marketing management, and management of the Occupational Safety and Health Environment (LK3). The target subjects of the activity are workshop managers and mechanics. Evaluation of training participants' satisfaction is carried out through customer satisfaction measurement instruments. The results of the training and mentoring service activities for small and micro car repair shops in Purworejo district to improve the competitiveness of these services are; 1) the service activities carried out at the "Karunia" Car Workshop, received a pretty good response. The indicators are that both the manager and the partner car repair mechanics take part in the activity from start to finish; 2) training and mentoring activities for car workshop managers and mechanics, have increased knowledge about injection technology and services for injection technology cars, entrepreneurship and marketing management, workshop administration systems, financial report recording, and environmental management, occupational safety and health (LK3 ); and 3) training and mentoring activities have provided provisions for car repair shop managers and mechanics to be better prepared in providing injection car service services.
\end{abstract}

Article Info: Submitted: 19/10/2020 | Revised: 05/11/2020 | Accepted: 14/11/2020 


\section{PENDAHULUAN}

Perkembangan jumlah industri otomotif saat ini belum diimbangi dengan pertumbuhan jumlah bengkel pendukung layanan purna jual. Akibatnya sering terjadi antrean cukup panjang kendaraan yang membutuhkan perawatan atau perbaikan. Kondisi tersebut terjadi karena bengkel yang ada hanya bisa melayani sekitar $60 \%$ dari kebutuhan layanan purna jual kendaraan, sehingga masih terbuka luas untuk bisnis perbengkelan di dalam negeri. Apalagi, industri otomotif juga membutuhkan keberadaan bengkel umum atau bengkel resmi (authorized) menjadi bagian dari jaringan layanan purna jual untuk memberi kemudahan bagi pelanggan yang kendaraannya bermasalah (Abdullah, 2013). Kondisi tersebut merupakan peluang berdirinya usaha jasa yaitu bengkel mobil. Bengkel mobil adalah suatu badan usaha yang bergerak dalam jasa perawatan dan perbaikan kendaraan bermotor (otomotif) yaitu mobil.

Bengkel perbaikan yang dilakukan oleh bengkel mobil adalah perbaikan body dan sasis, mesin, sistem elektrik, pengecatan dan pengelasan mobil (G. Rubiono, R. M. Yasi, 2017). Bisnis bengkel mobilpun bukan hanya bertumpu pada kegiatan pelayanan perawatan mobil atau jasa perawatan mobil saja. Terdapat faktor-faktor tertentu yang memang mampu mendukung kegiatan bisnis seperti fasilitas tempat yang cukup nyaman dan pelayanan kepada pelanggan. Untuk mempertahankan kelangsungan bisnisnya harus ditunjang dengan sistem, baik pembukuan atau pencatatan ataupun dari bidang manajemen yang handal (M. Sodiq, 2018).

Usaha bengkel mobil (UBM) merupakan usaha yang menarik ditinjau dari pasar dan permintaan pasar. UBM akan terus berkembang selama terjadi peningkatan jumlah penjualan mobil penumpang dan jumlah populasinya. Apabila UBM difokuskan pada mobil penumpang, maka tingkat prospek UBM mobil penumpang lebih tinggi dari UBM kendaraan umum dan angkutan karena UBM mobil penumpang melayani golongan menengah ke atas yang mampu membeli mobil pribadi, dan konsekuensinya akan membutuhkan perawatan dan perbaikan mobil milik pribadi mereka secara periodik selama mobil tersebut masih digunakan. Aspek manajemen memiliki peran penting dalam pengelolaan usaha bengkel. Minimnya ilmu manajemen dan pemasaran bengkel yang menjadi salah satu tidak suksesnya usaha (Solechan. S. Raharjo, 2016).

Mitra dalam kegiatan pengabdian ini, yaitu bengkel mobil "Karunia" juga menghadapi kondisi yang kurang lebih sama dengan gambaran pada bengkel kecil pada umumnya. Pada bengkel mobil "Karunia", kondisinya adalah tidak ada pembagian tugas yang jelas antara bidang administrasi dan operasi. Jabatan manajer, frontman (service advisor), chief mecanic, final inspector, tool man dipegang oleh pemilik bengkel. Sedangkan karyawan menempati posisi mecanic, yang mengerjakan operasi untuk memberikan jasa layanan yang diminta pelanggan dengan arahan dan kontrol langsung dari pemilik bengkel. Maka saat diterapkannya teknologi baru pada mobil, atau ketika bengkel ingin menambah jenis jasa layanannya, maka pemilik dituntut untuk memiliki kemampuan dan keahlian terhadap teknologi baru tersebut, yang kemudian ditularkan kepada karyawannya. Selain itu sistem administrasi bengkel belum terlaksana dengan tertib, tidak terkecuali dengan aktivitas pencatatan laporan keuangan.

Akibatnya tidak tersedianya data tentang customer, data karyawan kaitannya dengan sistem penggajian dan transaksi servis, data supplier, data barang/persediaan di bengkel, 
data servis yang dilakukan, data transaksi keluhan, data transaksi jenis servis dan penjualan, data karyawan, data pembayaran, dan data penerimaan bengkel, hal tersebut memunculkan persoalan lain yaitu, pemilik bengkel tidak mengetahui secara pasti kemajuan usahanya; tidak mengetahui tingkat kenaikan harga sparepart yang cenderung menyesuaikan dengan perubahan nilai tukar rupiah, akibatnya pemilik bengkel kesulitan menentukan harga pokok untuk jasa layanannya, jika terjadi pergantian sparepart; barang/persediaan di bengkel sering hilang dan baru diketahui ketika hendak digunakan; dan sering terjadi kesalahan dalam menghitung tagihan servis ke pelanggan. Disamng itu terkait dengan penerapan manajemen lingkungan keselamatan dan kesehatan kerja (LK3) di bengkel mobil "kurnia" belum dilaksanakan sepenuhnya. Karena pengusaha bengkel kurang memahami manajemen lingkungan keselamatan dan kesehatan kerja (LK3) dan manfaatnya dalam pelaksanaan penyelesaian pekerjaan atau suatu tugas.

Berdasarkan kondisi mitra tersebut, maka tim pengabdian progdi pendidikan teknik otomotif UM Purworejo melakukan kegiatan yang mencakup: a) memberikan bekal kemampuan tentang servis mobil berteknologi injeksi; b) memberikan wawasan tentang kewirausahaan dan manajemen pemasaran kepada pengelola dan karyawan bengkel mobil; c) memberikan bekal kemampuan untuk melaksanakan sistem administrasi bengkel, sparepart, dan operasional secara lebih baik; d) memberikan bekal kemampuan untuk menyusun laporan keuangan yang informatif; e) memberikan pengetahuan dan pemahaman yang baik tentang manajemen Lingkungan, Keselamatan dan Kesehatan Kerja (LK3) dan manfaatnya dalam pelaksanaan penyelesaian pekerjaan atau suatu tugas.

Dengan pelatihan dan pendampingan yang dilakukan diharapkan dapat: a) mengembangkan kegiatan kewirausahaan sesuai dengan kualitas dan kompetensi sdm yang dimiliki; b) meningkatkan kualitas SDM dalam meningkatkan kapasitas usaha dan daya saing pelayanan melalui pelatihan dan pendampingan; c) meningkatkan sarana dan prasarana bengkel mobil dengan hibah peralatan yang dapat mendukung dalam menawarkan jasa layanan servis mobil dengan teknologi injeksi. sehingga mitra bisa meningkatkan daya saing pelayanan dan tetap eksis ditengah persaingan yang sangat ketat, dan terjadinya perubahan atau kemajuan teknologi.

\section{METODE}

Waktu dan tempat kegiatan pengabdian dilaksanakan dilaksanakan dari bulan Juli sampai dengan bulan Agustus 2020 dilaboratoium bengkel pendidikan teknik otomotif UM Purworejo serta di Bengkel Mobil “Karunia”Jalan WR Supratman No.146 Tambakrejo Purworejo. Target kegiatan pengabdian yakni memberikan bekal pada mitra tentang servis mobil berteknologi injeksi; 1) memberikan wawasan manajemen pemasaran kepada pengelola dan karyawan usaha bengkel mobil; 2) memberikan bekal pada mitra melaksanakan sistem administrasi bengkel, sparepart, dan operasional secara lebih baik; 3) memberikan bekal pada mitra menyusun laporan keuangan yang informatif; dan 4) m6emberikan pengetahuan dan pemahaman pada mitra tentang manajemen Lingkungan, Keselamatan dan Kesehatan Kerja (LK3).

Subjek dari kegiatan pengabdian adalah pengelola dan tenaga mekanik Bengkel Mobil “Karunia”Jalan WR Supratman No. 146 Tambakrejo Purworejo. Adapun tahapan kegiatan pengabdian masyarakat ini dilaksanakan dalam tiga tahap untuk memecahkan 
permasalahan yang teridentifikasi, yaitu: Tahap I : Evaluasi strategi pengelolaan usaha bengkel yang sedang dijalankan. Pada tahapan kegiatan ini bertujuan untuk mengevaluasi strategi pengelolaan usaha bengkel yang sedang dijalankan.

Pada saat ini pengelolaan usaha bengkel mobil masih sangat sederhana, dengan jenis jasa layanan servis yang terbatas. Sebagai akibat dari terbatasnya pengetahuan dan pemahaman tentang manajemen bengkel, sumber dana, sarana dan prasarana, teknologi injeksi untuk mobil, kualitas SDM yang rendah, perencanaan keuangan, serta pencatatan laporan keuangan yang belum dilaksanakan secara rutin dan tertib; Tahap II : Pelatihan dan Pendampingan. Pada tahap kegiatan ini bertujuan untuk meningkatkan kemampuan dan keterampilan Sumber Daya Manusia (SDM) bengkel mobil dalam memberikan jasa layanan servis mobil injeksi, kewirausahaan dan manajemen pemasaran, sistem administrasi bengkel, sparepart, operasionalnya, penyusunan laporan keuangan yang informatif, dan meningkatkan pengetahuan dan pemahaman tentang manajemen LK3; dan Tahap III : Kegiatan Monitoring. Pada tahap kegiatan ini bertujuan untuk memonitor hasil kegiatan dari pelaksanaan pendampingan dan pelatihan dan juga dilakukan identifikasi hambatan-hambatan yang timbul selama pelatihan dan pendampingan berlangsung, dan disiapkan solusinya. Sebagai tahapan akhir dari kegiatan pengabdian Pelatihan dan pendampingan usaha kecil mikro bengkel mobil di kabupaten purworejo untuk meningkatkan daya saing pelayanan yaitu evaluasi kepuasan peserta pelatihan yang dilakukan melalui Instrumen Pengukuran Kepuasan Pelanggan.

\section{HASIL DAN PEMBAHASAN}

Kegiatan pengabdian pelatihan dan pendampingan usaha kecil mikro bengkel mobil di kabupaten purworejo untuk meningkatkan daya saing pelayanan ini dilaksanakan kurang lebih selama 2 bulan yang dimulai dari bulan Juli sampai dengan bulan Agustus 2020, dan tempat pelaksanaannya berada di laboratoium bengkel Pendidikan Teknik Otomotif UM Purworejo serta di bengkel mobil "Karunia" yang berlokasi di Jalan WR Supratman No.146 Tambakrejo Purworejo. Kegiatan pelatihan dan pendampingan yang dilaksanakan meliputi:

a. Pelatihan servis mobil berteknologi injeksi. Pelatihan servis mobil berteknologi injeksi difokuskan pada bagaimana menghasilkan jasa layanan servis mobil berteknologi injeksi, dan memberikan pemahaman tentang ukuran-ukuran perbaikan sesuai standar yang berlaku untuk meningkatkan kinerja bengkel mobil. Sehingga peluang pasar tetap bisa diraih dengan pemanfaatan sumberdaya secara maksimal. Sedangkan materi yang diberikan mencakup: electronic fuel injection dan sistem kerjanya, mendiagnosa kerusakan mobil dengan scan tool, selain itu praktik secara langsung pengoperasian scan tool tersebut. Pada pelatihan ini pengelola dan para karyawan bengkel tersebut (Gambar 1) memiliki kesempatan yang cukup untuk mempelajari bagaimana mengoperasikan scan tool dan juga peralatan pendukung yang lainnya; 


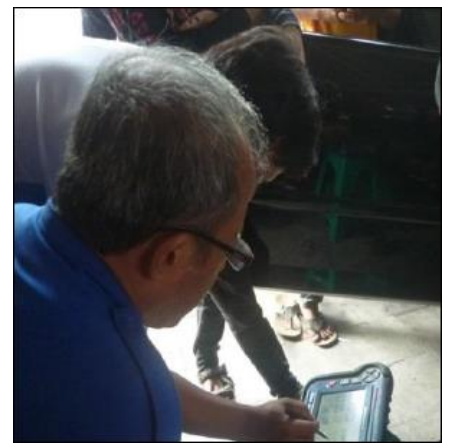

Gambar 1. Praktik penggunaan scanner

b. Pelatihan penerapan sistem administrasi bengkel, sparepart, dan operasionalnya. Pelatihan ini terutama ditujukan untuk meningkatkan kemampuan SDM pada kedua bengkel mobil dalam penyelenggaraan aktivitas administrasi dan pencatatan laporan keuangan, sehingga bisa diketahui kemajuan usahanya.

c. Adapun materi yang diberikan meliputi: administrasi bengkel dan penyusunan laporan keuangan yang informatif;

d. Pelatihan manajemen pemasaran usaha. Pelatihan manajemen pemasaran usaha diarahkan pada bagaimana pengelola bengkel mobil mengetahui dan memahami peluang pasar dalam dunia bisnis, dan wawasan kewirausahaan. Pelatihan ini juga memberikan bekal keahlian manajerial bagi pengelola bengkel mobil dalam menjalankan usahanya, selanjutnya menggunakan keahliannya untuk mengelola perubahan dan inovasi, memanfaatkan peluang, siap mengambil risiko, dan mampu menghitung potensi pasar;

e. Pelatihan manajemen lingkungan keselamatan dan kesehatan kerja (LK3). Pelatihan manajemen LK3 dimaksudkan agar pengelola dan karyawan bengkel mobil memiliki pemahaman tentang segala aspek keselamatan kerja, mengidentifikasikan bahaya, dan cara menangani risiko yang timbul dalam penyelesaian pekerjaan, dengan tetap mempertahankan jaminan bahwa pengendalian risiko ini sangat efektif. Selain itu untuk menyiapkan dan melengkapi semua karyawan dengan keterampilan yang diperlukan, pengetahuan dan semua informasi yang berhubungan dengan keselamatan pada operasi kerja, proses kerja dan perawatan fasilitas dan peralatan untuk memungkinkan mereka dapat melakukan pekerjaan dengan aman dan efisien. Kegiatan pelatihan dan pemaparan materi disajikan pada Gambar 2.

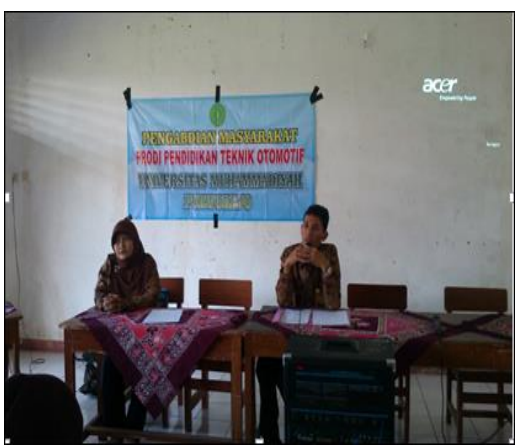

Gambar 2. Pelatihan manajemen bengkel 
f. Pelaksanaan Pendampingan. Pendampingan dilaksanakan dalam bulan JuniSeptember 2020 pada kedua mitra yaitu bengkel mobil "Karunia". Kegiatan pendampingan diberikan untuk mendukung usaha bengkel mobil yang tengah dijalani dan yang akan dijalankan. Materi pendampingan mencakup praktik pengoperasian peralatan untuk servis mobil injeksi berupa scanner yang berbasis PC dan bagaimana memberikan layanan servis mobil ke pelanggan, pengelolaan administrasi bengkel, dan penyusunan laporan keuangan. Praktik secara langsung diharapkan pengelola bengkel dapat mengaplikasikan materi yang disampaikan secara lebih mudah dan pengelola maupun karyawan bengkel mobil bisa secara langsung berkonsultasi dengan Tim Pelaksana Pengabdian. Disisi lain jika menemui kesulitan atau kendala, pengelola atau tenaga mekanik bengkel menjadi tahu bagaimana harus menyelesaikannya.

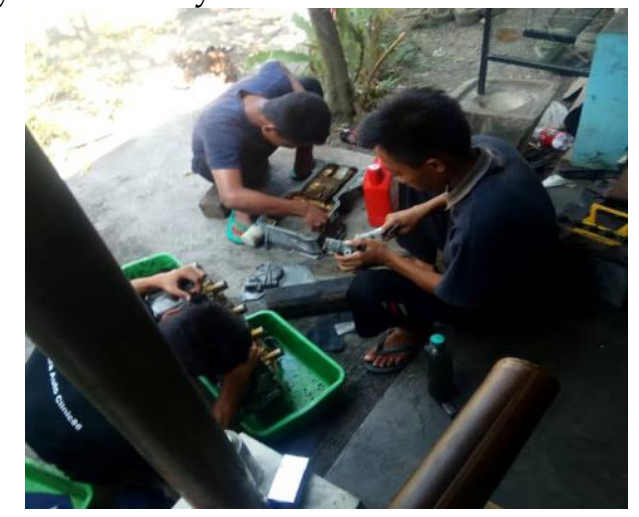

Gambar 3. pendampingan servis mobil

Kegiatan pelatihan dan pendampingan pada kedua pengelola dan karyawan bengkel mobil ini dapat dikategorikan berhasil dan memberikan manfaat positif. Indikatornya adalah pelaksanaan kegiatan secara keseluruhan, berikutnya terdapat peningkatan pengetahuan dan kemampuan pada SDM bengkel tentang layanan servis mobil injeksi, yang terutama adalah kesiapan untuk menawarkan jasa layanan servis mobil injeksi. Sehingga daya saing pelayanan terhadap konsumen dapat ditingkatkan.

Setelah keseluruhan program selesai dilaksanakan, maka penting untuk direncanakan keberlanjutan program tersebut. Evaluasi kepuasan peserta pelatihan dilakukan melalui Instrumen Pengukuran Kepuasan Pelanggan Bidang PPM kepada 6 responden dari 7 peserta dengan hasil ditunjukkan pada Tabel 1. 
Tabel 1. Kepuasan peserta kegiatan pengabdian

\begin{tabular}{|c|l|c|c|c|c|c|c|c|c||}
\hline \multirow{2}{*}{ No } & \multicolumn{1}{|c|}{ Pernyataan } & \multicolumn{7}{c|}{ Skor/persentase } \\
\cline { 3 - 9 } & & 1 & $\%$ & 2 & $\%$ & 3 & $\%$ & 4 & $\%$ \\
\hline 1 & $\begin{array}{l}\text { Kesesuaian kegiatan dengan } \\
\text { kebutuhan masyarakat }\end{array}$ & 0 & 0 & 1 & 5,6 & 9 & 50 & 8 & 44,4 \\
\hline 2 & $\begin{array}{l}\text { Kerjasama pengabdi dengan } \\
\text { masyarakat }\end{array}$ & 0 & 0 & 0 & 0 & 12 & 67,2 & 6 & 33,6 \\
\hline 3 & $\begin{array}{l}\text { Memunculkan aspek pemberdayaan } \\
\text { masyarakat }\end{array}$ & 0 & 0 & 3 & 16,8 & 9 & 50 & 6 & 33,6 \\
\hline 4 & $\begin{array}{l}\text { Meningkatkan motivasi masyarakat } \\
\text { untuk berkembang }\end{array}$ & 0 & 0 & 1 & 5,6 & 10 & 56 & 7 & 39,2 \\
\hline 5 & $\begin{array}{l}\text { Sikap/perilaku pengabdi di lokasi } \\
\text { pengabdian }\end{array}$ & 0 & 0 & 0 & 0 & 11 & 61,6 & 7 & 39,2 \\
\hline 6 & $\begin{array}{l}\text { Komunikasi/koordinasi dengan } \\
\text { penanggungjawab pengabdian }\end{array}$ & 0 & 0 & 0 & 0 & 14 & 78,4 & 4 & 22,4 \\
\hline 7 & $\begin{array}{l}\text { Kesesuaian waktu pelaksaan } \\
\text { dengan kegiatan masyarakat }\end{array}$ & 0 & 0 & 2 & 11,2 & 14 & 78,4 & 2 & 11,2 \\
\hline 8 & $\begin{array}{l}\text { Kesesuaian keahlian pengabdi } \\
\text { dengan kegiatan pengabdian }\end{array}$ & 0 & 0 & 1 & 5,6 & 8 & 44,4 & 9 & 50 \\
\hline 9 & $\begin{array}{l}\text { Kemampuan mendorong } \\
\text { kemandirian/swadaya masyarakat }\end{array}$ & 0 & 0 & 1 & 5,6 & 9 & 50 & 8 & 44,4 \\
\hline 10 & $\begin{array}{l}\text { Hasil pengabdian dapat } \\
\text { dimanfaatkan masyarakat }\end{array}$ & 0 & 0 & 0 & 0 & 10 & 56 & 8 & 44,4 \\
\hline \hline
\end{tabular}

Dari tabel 1 dapat diketahui bahwa rerata kepuasan peserta kegiatan pengabdian adalah: tidak ada satupun ( $0 \%$ ) yang kurang puas, 5\% menyatakan cukup puas, 58,9\% menyatakan baik/puas dan 36,1 \% menyatakan sangat baik/sangat puas, dengan demikian rerata kepuasan peserta adalah : $95 \%$ puas dan sangat puas, sedangkan $5 \%$ cukup puas. Dengan demikian hasil kegiatan pengabdian pelatihan dan pendampingan usaha kecil mikro bengkel mobil di kabupaten purworejo untuk meningkatkan daya saing pelayanan ini sudah baik. Sedangkan keberlanjutan program di lapangan setelah kegiatan pengabdian selesai dilaksanakan, meliputi; 1) monitoring pembuatan merek dan pendaftaran merek dagang/ jasa; 2) monitoring penerapan strategi pemasaran dalam kegiatan usaha; dan 3) sosialisasi pemasaran online dalam kegiatan bisnis beserta aspek hukum bagi mitra.

Berdasarkan hasil kegiatan pengabdian tersebut, pemilik bengkel membutuhkan suatu kegiatan dalam bentuk pelatihan yang dilanjutkan dengan proses pendampingan. Hal ini perlu dilakukan agar dapat melakukan perubahan manajemen dengan langsung menerapkannya sesuai kondisi kerja di bengkel. Penjelasan dengan contoh-contoh langsung di bengkel akan memudahkan memberikan pemahaman khususnya kepada para karyawan bengkel. Perubahan pola kerja akan membutuhkan waktu untuk mencapai suatu perubahan. Pemilik bengkel akan memerlukan suatu kiat atau strategi khusus agar para karyawannya mendukung pelaksanaan manajemen. Untuk itu diperlukan suatu argumen yang kuat agar para karyawan dapat menerima perubahan dengan baik. Argumen ini harus dapat menjelaskan bahwa perubahan pola kerja juga akan mendatangkan manfaat, keuntungan dan meringankan pekerjaan mereka. Dengan cara ini 
maka pelaksanaan manajemen akan dapat dilakukan dengan baik.

\section{SIMPULAN DAN SARAN}

Simpulan kegiatan pengabdian pelatihan dan pendampingan usaha kecil mikro bengkel mobil di kabupaten purworejo untuk meningkatkan daya saing pelayanan ini adalah; 1) Kegiatan pengabdian yang dilaksanakan pada Bengkel Mobil "Karunia", mendapatkan respon yang cukup baik. Indikatornya adalah baik pengelola maupun tenaga mekanik bengkel mobil mitra mengikuti kegiatan dari awal hingga akhir; 2) Kegiatan pelatihan dan pendampingan yang diberikan kepada pengelola dan tenaga mekanik bengkel mobil, telah meningkatkan pengetahuan tentang teknologi injeksi dan servis terhadap mobil berteknologi injeksi, kewirausahaan dan manajemen pemasaran, sistem administrasi bengkel, pencatatan laporan keuangan, dan manajemen lingkungan, keselamatan dan kesehatan kerja (LK3).; dan 3) Kegiatan pelatihan dan pendampingan telah memberikan bekal bagi pengelola dan tenaga mekanik bengkel mobil untuk lebih siap dalam memberikan jasa layanan servis mobil injeksi. Hal ini disebabkan karena kemampuan yang telah dimiliki dan adanya alat berupa scan tool.

Sebagai sarannya dalam kegiatan ini 1) pengabdian masyarakat kepakaran yang berjudul pelatihan dan pendampingan usaha kecil mikro bengkel mobil di Kabupaten Purworejo sangat membantu dalam mengatasi trouble shooting kendaraan mobil yang terjadi, sehingga kompetensi servis mobil berteknologi injeksi perlu ditingkatkan lagi; 2) karena keterbatasan waktu yang tersedia, diperlukan suatu kegiatan pelatihan lanjutan yang dapat meningkatkan kompetensi keahlian bidang otomotif; dan 3) hasil pelaksanaan kegiatan pengabdian masyarakat yang telah didapatkan ini, dapat dijadikan sebagai acuan awal oleh tim pelaksana lain dalam rangka peningkatan pelayanan usaha bengkel mobil di Kabupaten Purworejo.

\section{E. DAFTAR PUSTAKA}

Anonymous. "Perawatan Rutin Mobil Mesin Injeksi. Artikel diakses tanggal 23 Mei 2013 dari www.kiosban.com/mesin-mobil/

Keputusan Menteri Tenaga Kerja R.I. No. Kep.1135/MEN/1987 tentang Bendera Keselamatan Dan Kesehatan Kerja. Jakarta.

Kotler, Philip. (2000). Marketing Management. Edition Milenium. Northwestern. New YorkUSA.

N. Abdullah. (2013). Jumlah Bengkel Terpaut Jauh dengan Pertumbuhan Kendaraan. http://www.otomotif.bisnis.com, diakses tanggal 18 September 2017 .

Noe, A.,Raymond, et. al. (2010). Manajemen Sumber Daya Manusia-Mencapai Keunggulan Bersaing. Buku 1. Edisi 6. Salemba Empat. Jakarta.

Peraturan Menteri Tenaga Kerja R.I. No. Per.05/MEN/1996 tentang Sistem Manajemen Keselamatan dan Kesehatan Kerja. Jakarta.

Partomo, Titik Sartika \& Soejoedono, Abd. Rachman. (2004). Ekonomi Skala Kecil/Menengah dan Koperasi. Ghalia Indonesia. Jakarta. 


\section{SURYA ABDIMAS}

\section{Volume 4 Nomor 2, Oktober, 2020, pp: 44-52}

Available online at: http://jurnal.umpwr.ac.id/index.php/abdimas p-ISSN: 2580-3492 e-ISSN: 2581-0162

Robbins, P. Stephen \& Coulter, Mary. (2009). Manajemen. Edisi kedelapan. Jilid 1. P.T. Indeks. Jakarta.

Suryana. (2008). Kewirausahaan, Pedoman Praktis: Kiat dan Proses Menuju Sukses. Salemba Empat. Jakarta. 